\title{
Adsorption for environmental remediation: the use of activated carbon as a by-product from a biomass gasification plant compared with commercial activated carbon
}

\author{
A. S. Oliveira ${ }^{1,2}$, C. M. Cardoso ${ }^{1}$, C. G. Maia ${ }^{1} \&$ P. Brito ${ }^{1}$ \\ ${ }^{1}$ Instituto Politécnico de Portalegre, Portugal \\ ${ }^{2}$ Universidade Técnica de Lisboa, Portugal
}

\begin{abstract}
Activated carbon is a well known amorphous adsorbent for hydrophobic pollutants, having the ability to take in its porous structure molecules of very different sizes. Portalegre Polytechnic Institute has a pilot plant for biomass gasification for syngas production, the residues of which need remediation. The syngas production process produces tar rich liquid condensates and powdered carbon as main residues. The powdered carbon is in fact activated carbon once it results from partial combustion at high temperatures and so it can be used as an adsorbent for pollutant removal from any effluent. Condensates resulting from gasification are coloured and strongly odoured residues; rich in hydrocarbon contaminants usually known as tars. In this work, powdered carbon residue was used to adsorb the contaminants present in the condensate residue produced in the process. The adsorption process was shown to be highly efficient in the removal of odour and colour from gasification condensates and the results were not very much different from the ones obtained for commercial activated carbon. After being used for adsorption, the carbon residue can be reburned in the gasification plant (which also needs coal for the heating start up procedure) to promote a final destruction process of the adsorbed contaminants with production of freshly activated carbon.

Keywords: activated carbon, adsorption, biomass gasification, tars, condensates, remediation of biomass residues.
\end{abstract}




\section{Introduction}

Environmental remediation of residues and effluents containing dangerous pollutants is nowadays an issue of great concern and several strategies are being developed especially directed towards the treatment of carcinogenic, persistent and emergent contaminants [1-5].

Nowadays, activated carbon finds wide application in many areas, but especially in the environmental field. Aside from environmental pollution control, activated carbon is mainly used in industry in various liquid and gas phase adsorptions [6]. The use of activated carbon in water treatment for removal of substances responsible for taste and odour dates back to the late 1920s [7]. Activated carbon is able to adsorb a great range of substances due to the flexibility of its amorphous structure that in the same grain possesses pores of very different sizes (from submicropores with $(<0.4 \mathrm{~nm})$ to macropores of $(>50 \mathrm{~nm}))[6,7]$.

The groups of organics that are generally amenable to adsorption onto activated carbon include pesticides, herbicides, aromatic solvents, polynuclear aromatics, chlorinated aromatics, phenolics, chlorinated solvents, highmolecular-weight (HMW) aliphatic acids and aromatic acids, HMW amines and aromatic amines, fuels, esters, ethers, alcohols, surfactants, and soluble organic dyes. Compounds having low molecular weight (LMW) and high polarity, such as LMW amines, nitrosamines, glycols, and certain ethers, are not suitable to adsorption [8].

Activated carbon can be used in powder or granular form and its high adsorption ability is related with its extremely high porosity and hydrophobic internal surface to where hydrophobic pollutants are attracted and become adsorbed by physical interactions. After treatment with activated carbon, hydrophobic pollutants get adsorbed inside its internal surface and the streams under treatment become free of those substances [6,8].

Activated carbon becomes frequently used for water treatment after the $70 \mathrm{~s}$, especially because water quality standards for human use and consumption become highly restrictive and compulsory in what concerns the classes of compounds that can be present in water streams as well as their limits. Conventional treatments revealed not to be able to remove those from water streams and activated carbon become a more and more used treatment alternative since in small amounts it revealed to be able to remove odor and taste from water [6-8].

Activated carbon is obtained by burning wood under controlled conditions, between $800^{\circ} \mathrm{C}$ to $1000^{\circ} \mathrm{C}$, avoiding its total burning and the lost of porosity [6].

Biomass gasification for syngas production is a process where biomass is burned at high temperatures $\left(\sim 800-850^{\circ} \mathrm{C}\right)$ in the present of nonstequiometric amounts of oxygen producing byproducts that contaminate the gas stream (tars, mostly hydrocarbons), condensates (liquid phase, high hydrocarbon content) and unburned coal (solid phase, carbon). The carbon solid phase is originated from the uncompleted biomass combustion at high temperatures similar to those used to produce activated carbon. The resultant carbon residue has high porosity and 
considerable adsorption capacity and will be used in this work as adsorbent for remediation of condensates resultant from the gasification process [9].

At the Polytechnic Institute of Portalegre we have a system similar to that described above, where the effluents need to be remediated or find a final destination $[10,11]$.

It is worth remembering that activated carbon has limited adsorption capacity. After activated carbon pores become full of particles of removed pollutants it has no more adsorption capacity and activated carbon has to be changed by a new amount of unused adsorbent. Activated carbon adsorption capacity can be regenerated treating it at high temperatures in order to burn the adsorbed matter. Reactivation involves treating the spent carbon in a high temperature reactivation furnace to over $800^{\circ} \mathrm{C}$ [6]. During this treatment process, the undesirable organics on the carbon are thermally destroyed.

So, in our plant, used activated carbon can be further readmitted to the gasification plant as coal used to start the heating of the plant. In this way, activated carbon containing condensate contaminants, will remediate itself inside the gasification plant, whose high temperatures will be adequate to efficiently destroy the hydrocarbon contaminants removed from the condensates.

\section{Experimental section}

\subsection{Reagents and materials}

Activated carbon resultant from IPPortalegre's gasification power plant was used as adsorption powder. Commercial Activated carbon (Panreac, M=12.01) was used as standard activated carbon adsorption powder, as provided by fabricant, for efficiency comparative purposes.

Condensates resultant from IPPortalegre's gasification power plant were subjected to adsorption after one filtration step with filter paper $(\varnothing=110 \mathrm{~mm})$.

We further used bidistilled water prepared in the laboratory.

\subsubsection{Materials}

All Uv-vis absorption spectra were registered with a Cary $100 \mathrm{UV}$-vis absorption spectrophotometer.

A centrifuge (SIGMA 2K15) and a lab mounted water vacuum filtration apparatus composed by a Buchner filter plus kitasato were used to separate the activated carbon from the condensate and the corresponding dilutions, following all adsorption processes.

\subsection{Experimental procedure}

As stated above, liquid condensates and activated carbon resultant from IPPortalegre biomass gasification plant were used in this work. Then we also conducted tests which we used the condensates from IPPortalegre biomass gasification plant with commercial activated carbon for comparative purposes.

Initially we started by preparing different solutions of condensates $(0.5 \mathrm{~mL} / \mathrm{L}$; $5 \mathrm{~mL} / \mathrm{L} ; 25 \mathrm{~mL} / \mathrm{L} ; 100 \mathrm{~mL} / \mathrm{L} ; 500 \mathrm{~mL} / \mathrm{L}$ and $1000 \mathrm{~mL} / \mathrm{L})$, after having done its 
absorbance reading in the spectrophotometer (brand Cary 100BIO). These samples were designated by zero samples and they were used to start testing the activated carbon of biomass plant from IPPortalegre, in order to observe its efficiency in adsorption of compounds. For this purpose we used $0.5 \mathrm{~g}, 0.1 \mathrm{~g}$ and $0.05 \mathrm{~g}$ of activated carbon. We prepared triplicate samples of the various dilutions of the zero samples, then we add to which sample $0.05 \mathrm{~g}, 0.1 \mathrm{~g}$ and $0.5 \mathrm{~g}$ of activated carbon. The solution was stirred manually to increase the contact of the activated carbon with the sample and allowed to stand for a while, then it was filtered with the aid of filter paper $(\varnothing=110 \mathrm{~mm})$ to analyze in the spectrophotometer. After we plotted the curves for all samples and checked the efficiency of the activated carbon from the biomass plant IPPortalegre, we repeated the process but this time using $0.1 \mathrm{~g}$ of commercial active carbon.

\section{Results and discussion}

\subsection{Effect of adsorption of diluted condensates solutions on activated carbon resultant from the biomass gasification plant of IPPortalegre}

Figure 1 displays adsorption results of water diluted condensates solutions on activated carbon resultant from IPPortalegre's gasification power plant operation. Figures 1a) and $1 \mathrm{~b}$ ) present the UV-visible absorption spectra of different condensates dilutions in water. Since pure condensates show very intense absorption in the ultra-violet region, several dilutions in water were prepared $(0.5 \mathrm{~mL} / \mathrm{L} ; 5 \mathrm{~mL} / \mathrm{L} ; 25 \mathrm{~mL} / \mathrm{L} ; 100 \mathrm{~mL} / \mathrm{L} ; 500 \mathrm{~mL} / \mathrm{L}$ e $1000 \mathrm{~mL} / \mathrm{L})$. The absorption spectra of non-diluted condensate solutions were always out of scale when registered with $1 \mathrm{~cm}$ pathlength spectrophotometric cells, so all of them had to be registered with $1 \mathrm{~mm}$ cells (respectively Figures $1 \mathrm{~b}$ ), d), f) and h)). Figures 1b) to 1d) present the UV-visible absorption spectra of the same solution after adsorption over different amounts of activated carbon obtained as residue from the IPPortalegre's gasification power plant operation. Adsorption was tested for $0.05 ; 0.1$ and $0.5 \mathrm{~g}$ of activated carbon.

As can be seen in Figure 1 (see next page), condensates have a complex and very strong absorption (always above 4 a.u. of absorbance for pure tar), resultant from a very high mixture of compounds. The highest absorbances are located in the interval of $200-300 \mathrm{~nm}$, corresponding to aromatic rings which are an important characteristic of hydrocarbons. When the several tar dilutions were treated with activated carbon their absorbances always decreased according to the amount of activated carbon (more activated carbon used has adsorbent correspond to higher absorbance decrease and consequently to a bigger contaminants removal). As showed in the graphic $\mathrm{g}$ ) were $0.5 \mathrm{~g}$ of activated carbon were added, the treatment has been partially efficient because most of the highest absorbance disappeared to wavelengths higher than $250 \mathrm{~nm}$. Therefore it is possible to conclude that the carbon residues produced in the central can be used as adsorbent for removal of contaminants present in condensates. After treatment, an odourless and colourless water residue was obtained. 

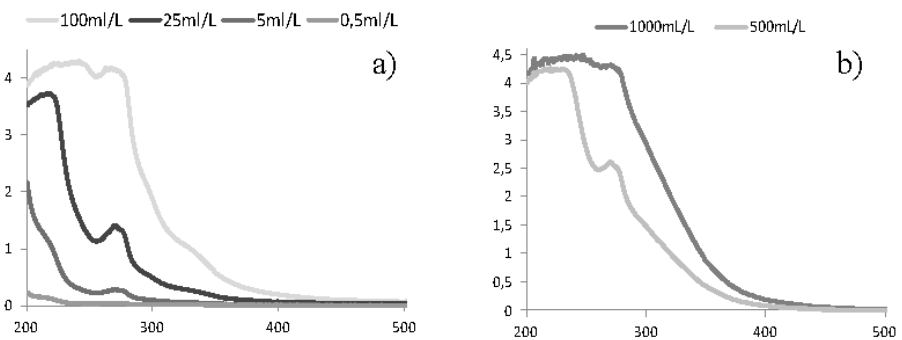

c)
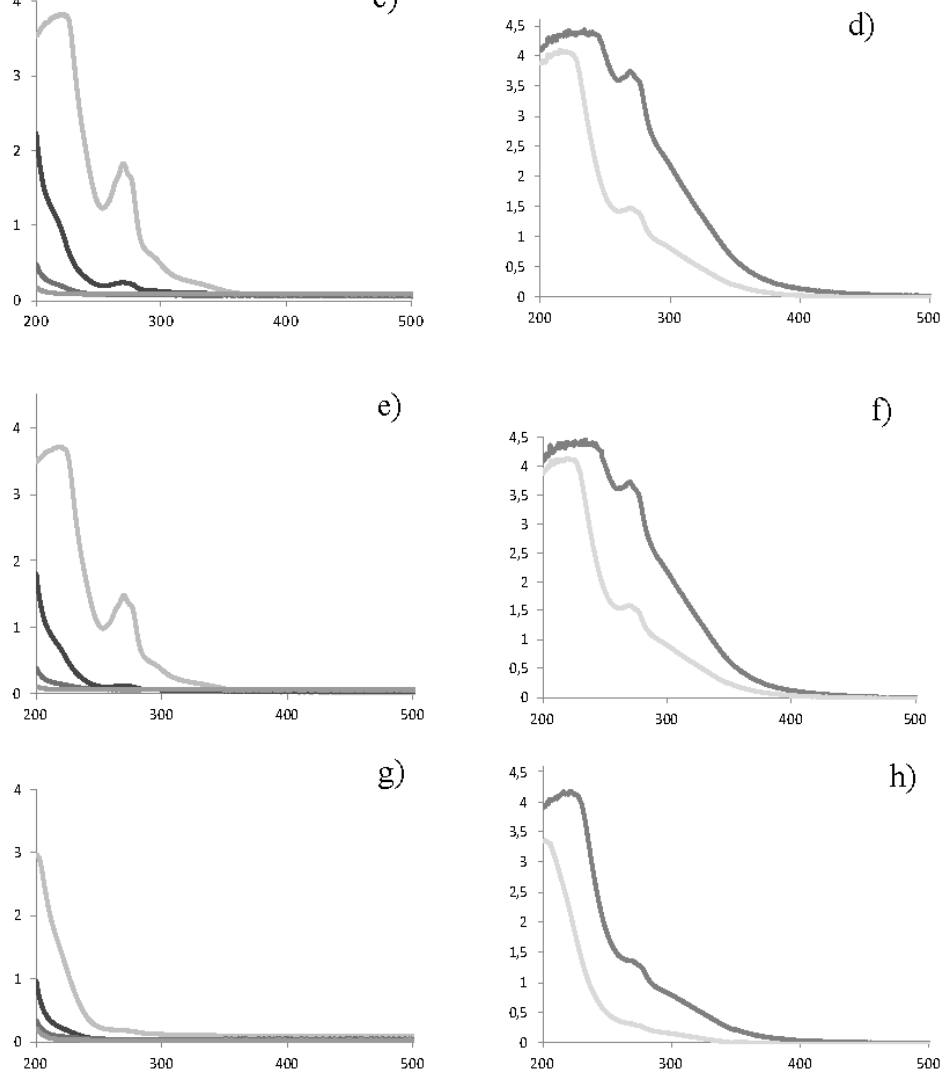

\section{Wavelength (nm)}

Figure 1: Ground state ultra-violet - visible absorption spectra of different dilutions $(0.5 \mathrm{~mL} / \mathrm{L} ; 5 \mathrm{~mL} / \mathrm{L} ; 25 \mathrm{~mL} / \mathrm{L} ; 100 \mathrm{~mL} / \mathrm{L} ; 500 \mathrm{~mL} / \mathrm{L}$ and $1000 \mathrm{~mL} / \mathrm{L}$ ) of condensates in water resultant from IPP's biomass gasification power plant operation; a), b) by themselves and after adsorption over c), d) $0.05 \mathrm{~g}$; e), f) $0.1 \mathrm{~g} ; \mathrm{g}$ ), h) $0.5 \mathrm{~g}$ of activated carbon resultant from operation of the same gasification plant. Spectra from b), d), f) and h) were registered with a $1 \mathrm{~mm}$ cell. 


\subsection{Comparison of the adsorption capacity with commercial activated carbon}

We further compared the process efficiency with that of commercial activated carbon, as presented in Figure 2. Figure 2 displays adsorption results of water diluted condensate solutions adsorbed on commercial activated carbon. Figure 2a) presents the UV-visible absorption spectra of different condensates dilutions in water. Since pure condensates show very intense absorption in the ultra-violet region, several dilutions in water were prepared $(0.5 \mathrm{~mL} / \mathrm{L} ; 5 \mathrm{~mL} / \mathrm{L}$; $25 \mathrm{~mL} / \mathrm{L} ; 100 \mathrm{~mL} / \mathrm{L} ; 500 \mathrm{~mL} / \mathrm{L}$ and $1000 \mathrm{~mL} / \mathrm{L})$. The absorption spectra of nondiluted condensates solutions were always out of scale even when registered with $1 \mathrm{~mm}$ pathlength spectrophotometric cells. Figure $2 \mathrm{~b}$ ) presents results from the addition of $0.1 \mathrm{~g}$ of commercial active carbon.

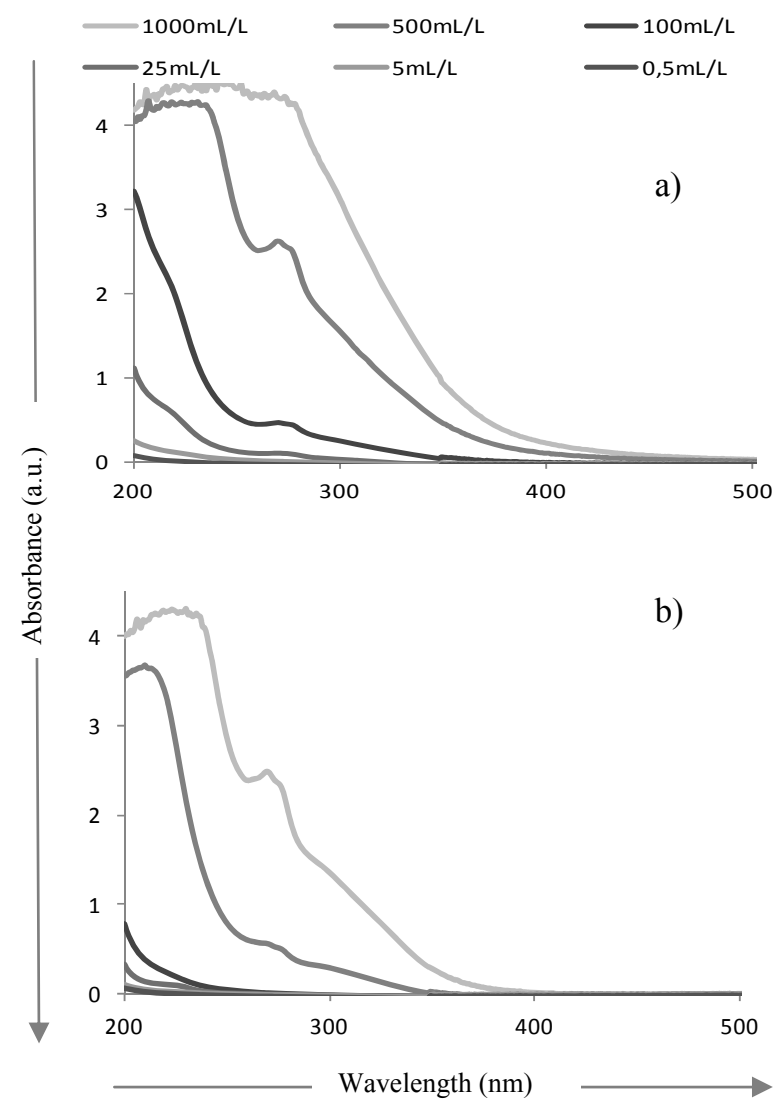

Figure 2: Ground state ultra-violet - visible absorption spectra of different dilutions $(0.5 \mathrm{~mL} / \mathrm{L} ; 5 \mathrm{~mL} / \mathrm{L} ; 25 \mathrm{~mL} / \mathrm{L} ; 100 \mathrm{~mL} / \mathrm{L} ; 500 \mathrm{~mL} / \mathrm{L}$ and $1000 \mathrm{~mL} / \mathrm{L}$ ) of condensates in water resultant from IPP's biomass gasification power plant operation; a) by themselves and after adsorption over b) $0.1 \mathrm{~g}$ of commercial activated carbon. Spectra a) and b) were registered with a $1 \mathrm{~mm}$ cell. 
If we compare Figure 2 with the graphic e) and f) from Figure 1 we can see that the commercial activated carbon it's not so efficiency as the activated carbon resultant from the biomass gasification plant, because commercial activated carbon it doesn't promote a decrease of absorbance as significant as the one resultant from the treatment with the same amount of activated carbon from the biomass gasification plant.

\section{Conclusions}

The solid powdered carbon residue resultant from the biomass gasification process for production of syngas at the Instituto Politécnico de Portalegre's Gasification Plant was efficiently used to remove colour and other as well as to substantially reduce the hydrocarbon content of the tar rich condensates resultant from the same process. The carbon powdered residue, produced at high temperatures (about $800^{\circ} \mathrm{C}$ ) showed to be more efficient on the adsorption and removal of contaminants present in the condensates than commercial activated carbon. After adsorptive treatment, condensates become an odour and colour less water residue. The carbon residue used as adsorption media can be further thermally regenerated readmitting it to the plant together with coal during plant start-up

\section{Acknowledgements}

The authors gratefully acknowledge project Altercexa I and II - medidas de Adaptação e Mitigação das Alterações Climáticas através da Produção de Energias Renováveis nas Regiões do Centro Extremadura e Alentejo.

\section{References}

[1] Oliveira A.S., Saggioro E.M., Pavesi T., Moreira J.C., Vieira Ferreira L.F. Solar Photochemistry for Environmental Remediation - Advanced Oxidation Processes for Industrial Wastewater Treatment (Chapter 15), Molecular Photochemistry - Various Aspects, ed. Satyen Saha pp. 355380, 2012. ISBN: 978-953-51-0446-9.

[2] Oliveira A.S., Maia C.G., Brito P., Boscencu R., Scoteanu R, Illie M., Vieira Ferreira L.F., Photodegradation of photodynamic therapy agents in aqueous $\mathrm{TiO}_{2}$ suspensions, Sustainable Development and Planning VI, 2013, C.A. Brebbia, E. Beriatos (editors)

[3] Güitekin, I., Ince, N.H., Synthetic endocrine disruptors in the environment and water remediation by advanced oxidation processes. Journal of Environmental Management, 85, pp. 816-832, 2007.

[4] Oliveira A.S., Saggioro E.M., Barbosa N., Mazzei A., Vieira Ferreira L. F., Moreira J., Surface Photocatalysis: A Study of the Thickness of $\mathrm{TiO}_{2}$ Layers on the Photocatalytic Decomposition of Soluble Indigo Blue Dye. Rev. Chim., 62(4), pp. 462-468, 2011. 
[5] Saggioro E., Oliveira A.S., Pavesi T., Maia C., Vieira Ferreira L. F., Moreira J., Use of Titanium Dioxide Photocatalysis on the Remediation of model textile wastewaters containing azo dyes. Molecules, 16, 1037010386, 2011.

[6] Bansal, R.P. and Goyal, M. (2005) Activated Carbon Adsorption, CRC Press, Taylor \& Francis Group, 6000 BrokenSound Parkway NW, Suite 300 Boca Raton, FL, USA 33487-2742.

[7] Hendricks, D. (2006) Water Treatment Unit Processes: Physical and Chemical, CRC Press. Printed in the USA.

[8] http:/www.chemvironcarbon.com/en/applications.effluent-water-treatment /wastewater. Accessed in 5/2/2014

[9] Balat M. (2009), Gasification of Biomass to Produce Gaseous Products, Energy Sources, Part A: Recovery, Utilization and Environmental Effects, $31516-526$.

[10] Brito, P.S.D, Rodrigues L.F, Calado, L., Oliveira, A.S., Thermal gasification of agro-industrial residues waste management and the environment VI, 2012, V. Popov, H. Itoh, C.A. Brebbia (editors).

[11] Brito, P.S.D., Oliveira A.S., Rodrigues, L.F., Energy valorization of solid vines pruning by thermal gasification in a pilot plant, Waste and biomass Valorization, (2013), 1877-2641. 